\title{
Salivary point-of-care technology
}

The advancements by biomedical engineering in dentistry bring revolution in the handling of oral diseases through different devices such as cutting instrument (slow and high-speed hand pieces), endomotor for root canal treatment, curing lights for dental composites, sterilization of instruments, laser technology minimal invasive technology, and computer-aided design-computer aided manufacture technology. Furthermore, this advancement also brings point-of-care (POC) technology toward salivary diagnostics quite helpful in early detection of oral and systemic diseases such as viruses, bacterial or fungal infections, cancers, and genetic disorders. POC technology is defined as "medical device used to conduct testing outside the laboratory at or near the site of patient care, including the patient's bedside, the doctor's office, and the patient's home." ${ }^{[1]}$ POC is a small, rapid, portable device capable of detecting absence or presence of diseases in human fluids. ${ }^{[2]}$ By the growing potential for this technology for the betterment of health care in developing world need to work on World Health Organization(WHO) provided guidelines. These guidelines are known as ASSURED (Affordability, Sensitivity, Specific, User-friendly, Rapid and robust, Equipment, Delivered). Salivary POC can operate easily, after saliva collection run into detection part and data will interpret easily through a computer screen or via Bluetooth to mobile. The advantage of this technology is to analyze or detect many analytes on one click through paper-based devices or chip-based devices. ${ }^{[3]}$ The best things develop or introduced in this technology are accuracy, multiplexibility, repeatability, and reproducibility. The broad vision of this technology is to cover not only early detection and risk assessment but also monitoring drug and metabolites in hospital-based setup and to evaluate patient's health 24/7. ${ }^{[4]}$ Microfluidic technology brings revolution in the field of diagnosis by developing "lab-on-a-chip" fluidic devices coupled with functional units, e.g., pumps, valves, and reactors. They are mostly fabricated with the help of glass, silicon, and polymers. ${ }^{[5]}$

Human saliva a miracle biofluid working in the oral cavity in a drastic way for the maintenance of human health. Not only maintenance but also represent the normal and abnormal disturbance of human health by their complex composition. ${ }^{[6]}$ Human saliva contains different mixtures of proteins, peptides, DNA, miRNA, exosomes, and electrolytes which can help in the diagnosis of diseases and this era is known as "liquid biopsy." [7,8] There are few sources for salivary biomarkers identified previously such as bacteria-derived biomarkers, host-derived inflammatory biomarkers, and host-derived biomarkers associated with soft tissue destruction. ${ }^{[9]}$ Currently, different fluids of human body such as blood (gold standard), serum, vaginal secretion, sperm, cerebrospinal fluid, urine, and sputum are all used as diagnostic fluid, but all have a different ways of sampling and with few complications. However, the attractive merits of human saliva banking for the disease detection is noninvasive, simple, and cheap sampling. ${ }^{[10]}$

Currently, salivary POC devices are divided into two categories: single biomarker detection-based and multiplexing detection-based devices. By the lab-on-a-chip technology improvement bring many tools in market namely Dentognostics (Germany) marketed Oral Risk Indicators ${ }^{\circledR}$ for rapid metalloproteinases- 8 testing in saliva, lateral force-based chromatography test strips for early screening of infectious diseases using saliva introduced by OraSure Technologies Inc., and UCLA SDx POC devices also for the detection of 8 different salivary biomarkers in 15 min. ${ }^{[11,12]}$

In conclusion, the parallel advances in salivaomics and microfluidic technology will make soon possible the clinical diagnosis low-cost, and patients get benefit from it as well for providing small sample volumes noninvasively.

\section{Zohaib Khurshid ${ }^{1}$}

'Department of Prosthodontics and Implantology, School of Dentistry, King Faisal University, Al-Hofuf, Saudi Arabia

Correspondence: Dr. Zohaib Khurshid Email: drzohaibkhurshid@gmail.com

\section{REFERENCES}

1. Song Y, Huang YY, Liu X, Zhang X, Ferrari M, Qin L, et al. Point-of-care technologies for molecular diagnostics using a drop of blood. Trends Biotechnol 2014;32:132-9.

2. Derda R, Gitaka J, Klapperich CM, Mace CR, Kumar AA, Lieberman M, 
et al. Enabling the development and deployment of next generation point-of-care diagnostics. PLoS Negl Trop Dis 2015;9:e0003676.

3. Hu J, Wang S, Wang L, Li F, Pingguan-Murphy B, Lu TJ, et al. Advances in paper-based point-of-care diagnostics. Biosens Bioelectron 2014;54:585-97.

4. Nie S, Henley WH, Miller SE, Zhang H, Mayer KM, Dennis PJ, et al. An automated integrated platform for rapid and sensitive multiplexed protein profiling using human saliva samples. Lab Chip 2014;14:1087-98.

5. Mehrotra P. Biosensors and their applications - A review. J Oral Biol Craniofacial Res 2016;6:153-9.

6. Wang A, Wang CP, Tu M, Wong DT. Oral biofluid biomarker research: Current status and emerging frontiers. Diagnostics (Basel) 2016;6. pii: E45.

7. Khurshid Z, Naseem M, Sheikh Z, Najeeb S, Shahab S, Zafar MS, et al. Oral antimicrobial peptides: Types and role in the oral cavity. Saudi Pharm J 2016;24:515-24.

8. Khurshid Z, Najeeb S, Mali M, Moin SF, Raza SQ, Zohaib S, et al. Histatin peptides: Pharmacological functions and their applications in dentistry. Saudi Pharm J 2017;25:25-31.

9. Ji S, Choi Y. Point-of-care diagnosis of periodontitis using saliva: Technically feasible but still a challenge. Front Cell Infect Microbiol 2015;5:65.

10. Khurshid Z, Zohaib S, Najeeb S, Zafar MS, Slowey PD, Almas K, et al. Human saliva collection devices for proteomics: An update. Int J Mol Sci 2016;17. pii: E846.
11. Walt DR, Blicharz TM, Hayman RB, Rissin DM, Bowden M, Siqueira WL, et al. Microsensor arrays for saliva diagnostics. Ann N Y Acad Sci 2007;1098:389-400.

12. Wei F, Wong DT. Point-of-care platforms for salivary diagnostics. Chin J Dent Res 2012;15:7-15.

This is an open access article distributed under the terms of the Creative Commons Attribution-NonCommercial-ShareAlike 3.0 License, which allows others to remix, tweak, and build upon the work non-commercially, as long as the author is credited and the new creations are licensed under the identical terms.

\begin{tabular}{|l|l|}
\hline \multicolumn{3}{|c|}{ Access this article online } \\
\hline Quick Response Code: & \\
\hline
\end{tabular}

How to cite this article: Khurshid Z. Salivary point-of-care technology. Eur J Dent 2018;12:1-2.

DOI: 10.4103/ejd.ejd_376_17 